\title{
Research in Cultural Governance for Border Areas in Yunnan Province
}

\author{
Xiaobo $\mathrm{He}$ \\ School of Public Management, Yunnan University of Finance and Economics, Kunming, P.R. China \\ 650221
}

hexiaobo921@hotmail.com

Keywords: cultural governance, border areas, ethnic group cultures, social development

\begin{abstract}
Since 2013, the status of culture has been lifted in a new height. Culture is regarded as a fact of "four-dimension as a unit" to consist the system of governance, paralleled with politics, economy and society. Cultural governance has been an organic part of national governance system. Yunnan is a important province with richest ethnic group cultures in China. Yunnan's culture owns its features as various ethnic groups, cultural diversity, low economic level, border frontier and so on. Consequently, the following passage summarized the features for Yunnan border culture, analyzed the influential factors for Yunnan's culture governance and predicted the tendency of cultural development.
\end{abstract}

With the new start of global cultural development strategy, more and more countries are making good use of culture and cultural policy to instruct the public and the individuals to go in a high reasonable and effective way. Cultural governance is one important part of social governance. It is always regarded as a whole system to unite culture and governance to distribute cultural resources and power make public cultural policy and deal with public cultural affairs. Nowadays, due to industrialization and urbanization, the social flow for urban and rural areas has been enhanced. People in different regions have different life styles and customs, which formed a challenge in fairness of public cultural service. Yunnan province is a kingdom famous for its various ethnic groups and cultural diversity in China, which lies to the border next to Vietnam, Laos and Cambodia. For this reason, the cultural phenomena there are so various and complicated, and also it has its traits in cultural development which are different from the ones in other areas. The research in cultural governance for border areas in Yunnan plays an important role in social stability and development.

\section{The cultural traits for border areas in Yunnan province}

A. Combine of Internationalization and Locality

Locality is a regional difference in the various native people's ideological consciousness, life styles, social customs and so on, which are formed and influenced in the local areas, cultures habits and time increase. The local region is the most elementary reason to form the local culture. The locality for Yunnan's culture means the universality of ethnic group's cultures. Yunnan is the province that boasts the most ethnic groups in China. Besides of Han people, there are other 25 ethnic groups and 15 of them are only existed in Yunnan. Small settlements and minorities mixed determine and create various ethnic groups and diversity of cultures. Yunnan's specific three dimensional terrain and climate condition create the cultural phenomena as language, clothes, living buildings, customs, religions and so on.

The internationalization for Yunnan's culture means open and mutual interactivity with the neighbor countries. The first, Yunnan lies in the southwest of China and lies to Vietnam, Myanmar and Laos. The total border line is 4060 kilometers. Since ancient times, Yunnan is the land passage to link with Southeast Asian countries. The second, the border people have a long history to trade with the other side. Nowadays, the need for international trade has increased. The strategy to develop Yunnan province as the international gate means facing the Southwest. At present, Yunnan is set up with 17 ports as Ruili, Wanding, Hekou, Tengchong, Daluo and so on. The third, the 
transnational ethnic groups lived in the borders' boundary line, there are 16 transnational ethnic groups such as Zhuang, Dai, Miao, Yao, Yi, Jinpo people and so on. The people live among at least 2 or 3 countries. Due to the historical tradition and realistic requirement, the transnational groups have being communicated so much as transnational marriage, trade, customs, religions and so on.

B. The Unitary of Convergence and Variability

As a branch of Chinese culture, Yunnan's border culture is similar and influential by the dominant culture. The first, there are 3 educational ways to teach and inherit cultures to the later generations: family education, school education and society education. In Yunnan's border culture, the main teaching way is school education too. The second, all people pursuit modern life styles. Whether people living in cities, rural areas, coastal regions or western borderland or not, they aim at better material and spirit life. The third, in the past, the state power is relatively lower than other central cities and provinces in Yunnan, because of the disadvantage of location in the remote, traffic inconvenience and information block.

The cultural stability doesn't mean cultural is immutable and frozen. Indeed, culture is in dynamic development all the time. The variability of Yunnan border culture can be understood by the following. The first, Yunnan's border culture is influenced by Han culture very much. China is a country consisted of many ethnic groups. From ancient times to the present, Han culture is the dominant culture even in minority dynasty as Yuan, Qing times. The second, Yunnan's border culture is the outcome of various ethnic group cultures' harmonious communication. In the long communication history, each ethnic group in Yunnan is friendly and tolerant. Mutual economic culture ad social communication has made the minorities in the co-existence and fusion. The third, Yunnan's culture is influenced by the neighbor countries a lot. The same festivals are the typical proof to explain the cultural exchange for Yunnan's ethnic groups and the neighbor countries as Water-splashing Festival.

C. Coexistence of Deconstruction and Reconstruction

Deconstruction is a critical method in post-structuralism. In original meaning, it means breaking up into something, clearing up something or revealing something.In Darrida's saying, a famous deconstructionist, deconstruction means breaking of structure.[1]However, deconstruction can mean the appearance of a new structure. Under the impact of wave of modernization, Yunnan border cultures vary greatly and are in strong deconstruction.

At first, the main cultural resources of Yunnan border cultures loss seriously, and some of them vary and convert so a lot, As the traditional cultural resources,some ethnic group's customs, habits, religion ceremonies and cultural activities have disappeared.Especially some important token for ethnic group's culture as language, costume are disappearing now. Especially for the young people, they are not proud of their ethnic group cultures any more, so the loss of minority's cultural resources is so serious.

The next, cultural inheritance for some ethnic groups are in the period of fracture. In some districts which are influenced a lot by the outer culture and condition, some young people are interested in modern urban living styles rather than traditional customs and ceremonies. So the participants of cultural inheritance are lack of cultural self-consciousness, which makes the cultural inheritance of ethnic groups be in a more difficult process. Even some excellent cultural elements are fail to be handed down from past generations.

What's more, cultural structure and traditional cultural forms are being broken. The native soil society is a concept provided by a famous sociologist Fei Xiaotong to describe and explain the social and cultural mode for traditional China. In traditional native soil society, almost all the people live as family and clan. Their villages are formed by the relations as blood or marriage.[3] However, modern city life style has drawn more and more young people in rural areas to go to city. The traditional social structure and cultural system are being in the risk of deconstruction and disappearance in ethnic group areas.

For these reasons, cultural reconstruction is urgent and necessary in minority areas. What is cultural reconstruction? It means the reconstruction of culture. It is the human's recognition for the existing cultural phenomena. It is the process that humans recreate, rework to certain cultural 
phenomenon. The various cultural communications and inter-activities for different ethnic groups are the cultural reconstruction process. Cultural reconstruction is not a brief process for cultural element collection Indeed, it is a process of dynamic reproduction of cultures, and it is full of subjective consciousness.

D. Melt of Cultural Specificity and Diversity

Yunnan is an the primary stage of socialism with low-level infrastructure construction, which is the key restriction to stop the whole development for the west minority areas. In this point, different regions in Yunnan face the same difficulty. However, Yunnan has the most ethnic groups. The history, complexity and imbalance for different minorities in economy, culture and society, which has formed the specificity of Yunnan's culture and made it in difficulty.

For one thing, Yunnan's environment is full of diversities. It is the fact that Yunnan is the biodiversity richest areas with the most complicated natural conditions in China.

For another, the uniqueness and richness of culture resources mean the diversity of cultures in Yunnan minority areas. Yunnan does not only own the name of "plant kingdom” , “animals kingdom" but also "ethnic group kingdom". Yunnan is one of the most abundant areas in ethnic groups and cultures in the world. It is a museum for ethnic groups cultures. In the rich cultural resources, ethnic group’s cultures are one of the most important resources.

\section{The influential factors to enforce cultural governance}

\section{A. Geographical Border Area}

In cultural geography, the cultural geographical research based on the unit as districts can most reflect the region's uniqueness and specificity of cultures. Any culture's forming should taken into account geographical factor. Yunnan and other Southeast Asian countries as Laos,Vietnam share the same mountains and rivers as Lancang River named Mengong River in other countries. Ethnic groups and cultures in these areas and countries has a long history of communication. The reason for the connection is the geographical border area at first.

B. Complexity and Diversity of Ethnic Groups and cultures

CPC Yunnan Province Committee and government has made one of the significant development strategies which is to construct Yunnan as a great province full of ethnic groups cultures. Ethnic group culture is one of the most exploitable resources full if attraction and sustainable development tendency. Even though almost minority cultures are mixed and melted, the group relations are various. For example, conflict and melt are the two sides of a coin, but also they coexist in the different groups cultural communication and interactivity.

C. Imbalance of Economic, Cultural and Social Development

One of the most obvious and significant traits for Yunnan's development is the imbalance of economic, cultural and social development. The imbalance doesn't only mean the difference in the various region but also the differentiation in the same districts. For example, Bai people and Naxi people both live in the west of Yunnan province. As early as Tang and Song Dynasty, they absorbed the developed Han culture. Especially their agricultural economy was influenced by Han culture a lot. So the culture and social development for Bai people and Naxi people are advanced. Their cultures are very open. However, for Jinuo people, Dulong people who live in the border of Yunnan province, the geographical condition is serious and difficult, so they are not so open and developed. Even in the 1950s, these ethnic groups were in the primitive society period.

D. Exploit and Inheritance for Ethnic Groups Cultures

It is an important research topic and difficulty for academic researchers and government officers to improve the cultural communication and melt and also keep the features for ethnic group cultures under the impact of globalization. To make the object---construction of national culture province come true, the key is to change cultural resources into economic advantages. So exploit and inheritance for ethnic groups cultures is so important in the development road of national cultural industry.

E. Cooperation for Government Authority and Local Social Power 
Rural villages are the main consisted units in Yunnan province. Rural villages are the elementary units for national power construction. Due to the orientated official system of China's culture, government authority always is one-way fashion to the elementary units. So government authority is powerful, mandatory and direct. The local social units have no choice except acceptance and enforcement. However patriarchy elite religion leaders and other community organizations are the very important power to lead and govern the whole local society. It is a necessary supplements to make rural areas stable and advanced come true.

F. Cultivation of Cultural Consciousness and National Consciousness

At present, Yunnan ethnic group culture is in the risk of cultural deconstruction. In the appeal of academe and government, all level governments have enforced a series of measures and policies to protect and inherit excellent traditional cultures.But the most important above these is people's cultural consciousness and national consciousness. Only by the means of cultivation of cultural and national consciousness, can the whole local society get a dynamic power for development.

\section{Tendency for the development of Yunnan border cultures}

A. In the Impact of Modernization, the Development Environment for Traditional Cultures Are Facing of Great Changes.

In the impact of Modernization and dominant culture as Han, the traditional social structure has been dismissed for some ethnic groups. Some ceremonies for cultural activities have been simplified. Some cultural developments and inheritance are out of people's mind. The environment for traditional cultures is weak more and more. Because more and more young people are attracted by modern city styles, they are not proud of their own minority cultures. The traditional excellent minority cultures are placed in the process of breaking and fracture.

B. Some Minority Cultures Are in the Risk of Continuous Fading, Even Though Some of Them Ate Striving on the Road of Innovation

Recently, the distance for the imbalance of the whole local society has been strengthened. Because the structure of minority distribution has been formed long ago, also the imbalance indeed existed long before. All minorities have been taken the advantage of environment to develop themselves. In human history, almost they formed a symbiotic relationship. However, in the impact of market economy, in some modern and commercial areas, their traditional minority cultures and changed into economic profits relatively easy and rapid, such as some tourism areas.

C. Non-synchronization of Economic, Cultural and Social Development May Cause Cultural Lag

Cultural lag is a concept provided by American sociologist Ogborne. It aims to describe the problems caused by the non-synchronization of economics, cultural and social development.[3]From the perspective of cultural lag, in the process of social change, material cultures and scientific technologies are changed at the soonest, and institutions and consciousness are the slowest. So a delay of the whole development can emerge. According to some sociologists' saying, the delay can last for a long time.[4] The delay must cause a series of social problems as cultural lag.

D. Various Ethnic Group Cultures Will Be Changed In Conflicts, but Cultural Melt Is the Main Tendency

Even though various ethnic group cultures all have obvious characteristics, cultural communication must be in the process of adaption, conflict and melting.[5]Generally speaking, cultural melt is the main tendency. However, it is inevitable for some culture parts to be in the opposite of conflict in process of melting. With the more communication and connection for various ethnic groups in politics, economy, culture and technology, their cultures will be changed and melted spontaneously, which is a natural and peaceful gradual process.

All in all, Yunnan border area has its own cultural features. These features are related to geographical location, diversity of ethnic groups and cultures, imbalance of society, government authority enforced and minority consciousness and so on. Only know about the influential factors to form the cultural features, can we predict the tendency of cultural development. Maybe some social 
problem would appear in the process of cultural communication, but cultural melting is the main tendency. Also because of these, human society can only develop in the process of cultural conflicts and melting.

\section{References}

[1] Zheng Hangsheng, Sociology, [M] Beijing: Renmin Press of China, 1998, P121(in Chinese)

[2] Fei Xiaotong, Xiangtu China,[M] Beijing: San Lian Press,1988, P12(in Chinese)

[3] Ming Yueling, Cultural Reconstruction and Protection of National Traditional Cultures, [J] Academic Journal of Central Minority University, 2007, P71(in Chinese)

[4] Chen Yanmei, Reconstruction for Minority Traditional Cultures in West Areas from the Perspective of Modern Context [J] Academic Journal of Qujing Normal Institute,2005, P70(in Chinese)

[5] Tong Xing, Developed Sociology and Chinese Modernization [M] Social Science and Documentary Press,2004, P36(in Chinese) 